\title{
Anticipating Stage Two: Assessing the Development of Meaningful Use and EMR Deployment
}

\author{
Nicolas P. Terry*
}

\section{INTRODUCTION}

In an earlier article I described the context and process of the Obama Administration's "Meaningful Use" ("MU"), the touchstone by which healthcare providers would qualify for stimulus funds made available by the Health Information Technology for Economic and Clinical Health Act ("HITECH"). 'Despite President Bush's commitment in 2004 to adopting a national Electronic Health Records system, by 2009 only seventeen percent of U.S. doctors and ten percent of hospitals had even basic Electronic Medical Record ("EMR") systems. Moreover, fewer than two percent of U.S. hospitals had comprehensive systems.

While the most frequently cited reason for Health Information Technology's ("HIT") low adoption rate has been high cost, the far more nuanced barrier has been market failure, even multiple market failures. Much of the savings from EMR accrue to payers, such as health insurers, rather than the health care providers actually investing in the technology. As a result, it has been difficult to make the Return on Investment ("ROI") business case for the adoption of EMR products.

This article begins by briefly restating the concepts behind the "meaningful use of certified EMR technology" and the types of requirements included in the MU stage 1 regulation of 2010 . Second, the article provides additional context for the design of stages 2 and 3, noting, for example, the impact of more general healthcare reform and some studies that have been critical of the MU strategy. Third, the article briefly explains the processes behind the development of stage 2 and the criticisms leveled at early drafts. Finally, with Department of Health and Human Services

\footnotetext{
${ }^{*}$ Hall Render Professor of Law and Co-Director of Hall Center for Law and Health, Indiana University Robert H. McKinneySchool of Law. Email: npterry@iupui.edu. Many thanks to Colleen Zern, Amanda Wong, and Professor Margaret McDermott for their excellent research assistance.

1. Nicolas P. Terry, Certification and Meaningful Use of Electronic Health Records: Reframing Adoption as a Quality and Reimbursement Imperative, 8 IND. HEALTH L. REV. 45, 45-68 (2011).
} 
("HHS") Agencies apparently once again bowing to HIT and healthcare industry pressure (or, depending on your perspective, showing flexibility), some key questions are posed as to the eventual success of the subsidy program.

\section{HITECH AND STAGE 1 RECALLED}

\section{A. HITECH and ARRA}

The combined funding from the American Recovery and Reinvestment Act of 2009 ("ARRA") and HITECH provided roughly \$30 billion for HHS Agencies: approximately $\$ 27$ billion for the Centers for Medicare \& Medicaid Services ("CMS") and $\$ 2$ billion for the Office of the National Coordinator ("ONC"). With these budgets, CMS is funding the EMR incentive program while $\mathrm{ONC}$ provides coordination, planning, and a national "help desk." ONC is also funding state and regional initiatives through grants and loans. Medicaid and Medicare incentive payments will be made to non-hospital-based doctors ("eligible providers", hereinafter "EP") and eligible hospitals. For example, a physician who participates in the full five-year program could receive the maximum subsidy of $\$ 44,000$ through Medicare (slightly more on a different timeline for the Medicaid program). Hospital-employed physicians are expressly excluded from the reimbursement opportunity as it is assumed they will have access to their hospital's EMR systems. However, hospitals themselves are eligible for reimbursement with a $\$ 2$ million baseline and thereafter a formula based on the number of inpatient discharges. Currently there are approximately 500,000 eligible providers and 5,000 eligible institutions. HITECH provides that to qualify for such payments the provider must make a "meaningful use of certified EMR technology."

\section{B. Meaningful Use and Certification}

Meaningful Use is a powerful but complex concept. It is better understood as a series of concepts arranged in a relatively hierarchical matrix consisting of goals, objectives, and measures (or compliance metrics) expressed across a timeline, and divided into three stages.

At the base of MU are the root outcome goals, long accepted as canonical in HIT, but expressed anew in HITECH: (1) improving the quality, safety, and efficiency of care while reducing disparities; (2) engaging patients and families in their care; (3) promoting public and population health; (4) improving care coordination; and (5) promoting EMR privacy and security. Objectives are the sub-goals derived from the HITECH goals. Measures are the reporting tools that represent compliance, typically with a usage "floor," to report progress towards the Objectives. 
The stage 1 regulation was published in July $2010^{2}$ and established a two-tier, core/menu model. This core/menu approach rotated around a set of fifteen "core objectives" that eligible providers and hospitals must satisfy to qualify for EMR funding and a "menu set" of ten objectives (twelve for professionals) from which five must be chosen and fulfilled. Each group of objectives includes a series of core (or mandatory) criteria and a series of menu criteria. Each criterion is accompanied by an outcome. For example, the fifteen objectives in the EP core set include the use of computerized physician order entry ("CPOE") for medication orders and the documentation of the smoking status of patients thirteen years old or older. The menu set includes objectives such as incorporating clinical lab test results into the record as structured data and providing patients with timely electronic access to their health information.

The stage 1 final rule is considerably less rigorous than the proposed rule that had foreshadowed it. Industry pushback and Congressional criticism led CMS/ONC to reduce provider eligibility objectives by introducing the core set/menu set distinction and to reduce the outcome measures.

While the MU rule applies to providers who wish to benefit from stimulus funding, the Certification rule applies to the technology those providers will actually use. ${ }^{3}$ Before "meaningful use of certified EMR technology" could become operational, regulators had to address the certified question. This involved two issues: the issuance of the certification standards themselves and a method of recognizing organizations that would apply those standards to proffered records technologies (i.e., actually certify EMR products).

The certification standards rule provides for the minimum specifications necessary to build and have certified an EMR system. Such specifications include the ability to record and chart vital signs, the maintenance of active medication lists, the maintenance of medication allergy lists, the ability to include laboratory test results, and the capability to generate lists of patients with specific conditions. As to who would perform the certification, a temporary program was implemented that is due to expire at the end of 2011. ${ }^{4}$ A Permanent Certification Program regulation was published in January 2011. ${ }^{5}$ The National Coordinator will use the permanent program to

2. Electronic Health Record Incentive Program, 75 Fed. Reg. 1844, 1935 (Jan. 13, 2010) (to be codified at 42 C.F.R. pts. $412,413,422,495$ ).

3. Health Information Technology: Initial Set of Standards, Implementation Specifications, and Certification Criteria for Electronic Health Record Technology, 75 Fed. Reg. 2014 (Jan. 13, 2010) (to be codified at 45 C.F.R. pt. 170).

4. Establishment of the Temporary Certification Program for Health Information Technology, 75 Fed. Reg. 36158, 36161-36184 (June 24, 2010) (to be codified at 45 C.F.R. pt. 170).

5. Establishment of the Permanent Certification Program for Health Information Technology, 76 Fed. Reg. 1262 (Jan. 7, 2011) (to be codified at 45 C.F.R. pt. 170). 
authorize organizations to certify EMR technology, such as Complete EMRs and/or EMR Modules. The transition from the temporary to permanent programs likely will occur in late 2011 or early 2012. The National Institute of Standards and Technology ("NIST") will accredit testing organizations and develop test tools and procedures. Every three years ONC will appoint an ONC-approved accreditor ("ONC-AA"), and that body will accredit other organizations (ONC-Authorized Certification Bodies or "ONC-ACBs" that replace the ONC-ATCBs under the temporary program) to actually accredit the technologies. ${ }^{6}$

\section{INTERREGNUM EVENTS: BETWEEN STAGES 1 AND 2}

CMS/ONC faced some difficult hurdles with involving industry players in the MU process. Healthcare providers had lagged behind the HIT curve and, while keen to have the government fund a proportion of their HIT upgrade costs, had not planned or budgeted for major change. Furthermore, the EMR industry was composed of hundreds of vendors, few of which were known for nimbleness or innovation. Consistent with its "escalator" model ${ }^{7} \mathrm{CMS} / \mathrm{ONC}$ hoped that the concessions it made between the stage 1 proposed and final rules would maximize participation and that the agencies could ramp up the MU criteria for the later stages.

No doubt a period of relative stability and steady progression in the promulgation of stage 1 of MU would have helped this process. In fact, stage 1 was followed by a period of considerable disruption. First, the leadership of the project was to undergo significant changes. Second, MU and HIT found themselves being embroiled in the broader Healthcare Reform of the Patient Protection and Affordable Care Act (Affordable Care Act, or "ACA"), particularly with regard to Accountable Care Organizations ("ACOs"). Third, issues have arisen as to the soundness of the federal government's approach to EMRs, data and interconnectivity, prompting broader questions about how best to stimulate innovation in the EMR space.

\section{A. Leadership Change and Other Challenges}

On March 20, 2009, Dr. David Blumenthal, a Harvard Medical School professor and director of the Institute for Health Policy at Massachusetts General Hospital, was announced as the third ONC coordinator. President

6. See Office Nat'l Coordinator for Health Info. Tech, ONC-Authorized Testing and Certification Bodies (Dec. 28 2010), http://healthit.hhs.gov/portal/server.pt /community/healthit_hhs_gov_oncauthorized_testing_and_certification_bodies/ 3120 .

7. See Joseph Conn, $C M \bar{S}$ Official: $\$ 400$ Million in EHR Incentive Payments Issued, MODERN HEALTHCARE (Aug. 4, 2011), http://www.modernhealthcare.com /article/20110804/NEWS/308049959/0\#. 
Obama's first coordinator was also the first statutorily recognized office within HHS with an independent budget. ${ }^{8}$

Having shepherded the first $\mathrm{MU}$ and Certification regulations and established himself as the public and well-respected face of the federal HIT movement, Dr. Blumenthal surprisingly resigned on February 3, 2011, to return to his faculty position. Subsequently, Dr. Blumenthal was also named the Chair of the Commonwealth Fund's Commission on a High Performance Health System. ${ }^{9}$ There was speculation at the time of Dr. Blumenthal's resignation that the ONC position was becoming increasingly challenging. The President's Council of Advisors on Science and Technology ("PCAST") report, discussed below, had been critical of some ONC fundamentals, there were rumors that Congress was considering a reduction in CMS/ONC funding, and the healthcare and HIT industries were increasing pressure on the government to ease up on the next stages of MU. $^{10}$

In April 2011, Secretary Kathleen Sebelius named Dr. Farzad Mostashari as the new National Coordinator for Health Information Technology. Dr. Mostashari had served as Deputy National Coordinator for Programs and Policy within the ONC during most of the Blumenthal era and prior to that had served as Assistant Commissioner at the New York City Department of Health and Mental Hygiene."

\section{B. Healthcare Reform (and ACOs)}

In the first blush of victory after the passage of healthcare reform, the administration was eager to celebrate HITECH and ACA as related legislation. For example, Dr. Blumenthal celebrated healthcare reform with these words, "[ACA] marks a new era in American health care. Yet in many

8. Press Release, U.S. Dept. of Health \& Human Serv. HHS Names David Blumenthal As National Coordinator for Health Information Technology, (Mar. 20, 2009), http://www.hhs.gov/news/press/2009pres/03/20090320b.html.

9. Commonwealth Fund, Commission on a High Performance Health System (2011), http://www.commonwealthfund.org/Content/Program-Areas/Health-Reform-Policy/

Commission-on-a-High-Performance-Health-System.aspx.

10. Joseph Conn, Blumental to Step Down From ONC, Modern HealthCare, Feb. 3, 2011, available at $\mathrm{http} / / / \mathrm{www}$. modernhealthcare.com/article/20110203/NEWS/302039957/; Steve Lohr, Carrots, Sticks and Digital Health Records, N.Y. TimES, Feb. 26, 2011, available at $\mathrm{http}: / / \mathrm{www}$.nytimes.com/2011/02/27/business/27unboxed.html?scp=1\&sq= unboxed\&st=cse; Diana Manos, Mostashari's ONC Won't Be As 'Easy' To Run As Blumenthal's, HEALTHCARE IT NEws, May 04, 2011, http://www.healthcareitnews.com/news /mostasharis-onc-wont-be-easy-run-blumenthals. See generally Phil Galewitz \& Christopher Weaver, Blumenthal To Leave Obama's Health IT Office, KAISER HeAlth News, Feb. 03, 2011, http://www.kaiserhealthnews.org/Stories/2011/February

103/Blumenthal.aspx.

11. Diana Manos, New ONC Chief, HealthCare IT News, May 04, 2011, http://www.healthcareitnews.com/news/new-onc-chief. 
ways, this era began more than a year earlier, with the passage of ... [HITECH]." 12 Obviously there are some thematic relationships between the two pieces of legislation. Indeed, Dr. Blumenthal and his HHS colleagues promoted the synergy between their HIT work and ACA's goals of improving quality, reducing costs, and accelerating outcomes research.

In today's somewhat darker days for healthcare reform, that linkage between HITECH and ACA may be harder to navigate. The poster child for linkage is the proposed ACO regulation. ${ }^{13}$ Officially, as laboratories for future healthcare models, ACOs are expected to innovate through their adoption of HIT ("It will draw upon the best, most advanced models of care, using modern technologies, including telehealth and electronic health records, and other tools to continually reinvent care in the modern age"14).

As originally conceptualized ACOs would require (maybe even revolve around) robust HIT systems in order to integrate the data flow between the participants and to provide outcomes reporting. Future ONC Coordinator Mostashari commented on the draft regulation as follows: "Health IT tools are an essential foundation to support the kinds of coordinated, patientcentered, and accountable care envisioned by the ACO program," and noted that the overlap between the clinical quality measures used in the MU program and the proposed ACO rule "strongly signals a desire for even greater alignment of the reporting requirements for ACOs and MU, including through eventual reporting of clinical quality measures directly from EHRs." 15

Thus, HIT requirements and synchronization with MU pervaded the ACO proposed regulation. For example, the meaningfully used EMR was to be the favored method for collecting outcomes and other data from ACO participants, and another requirement demanded that "at least 50 percent of an ACO's primary care physicians must be meaningful EMR users, using certified EMR technology. ..."16

However, as the wheels threatened to come off the ACO proposal, ${ }^{17}$

12. Melinda B. Buntin et al., Health Information Technology: Laying the Infrastructure for National Health Reform, 29 HeALTH AFF. 1214, 1214 (2010).

13. Medicare Program; Medicare Shared Savings Program: Accountable Care Organizations, 76 Fed. Reg. 19528 (Apr. 7, 2011) (to be codified at 42 C.F.R. pt. 425) [hereinafter Medicare Shared Savings Program].

14. Id. at 19533 .

15. Farzad Mostashari, Proposed ACO Rule A Change for Delivery System Transformation, HEALTHIT BUZZ (Apr. 1, 2011, 6:32 PM), http://www.healthit.gov/buzzblog/from-the-onc-desk/proposed-aco-rule-change-delivery-system-transformation/.

16. Medicare Shared Savings Program, supra note 13, at 19648.

17. See, e.g., Steven Lieberman, Proposed CMS Regulation Kills ACOs Softly, HeaLTH AfF. BLOG (Apr. 6, 2011, 11:38 AM), http://healthaffairs.org/blog/2011/04/06/proposedcms-regulation-kills-acos-softly/. 
some of the criticisms targeted the HIT proposals. ${ }^{18}$ More formally, the AMA called the fifty percent rule "premature" and "strongly recommend[ed] that ACOs should have the flexibility to come up with their own percentage requirements for meeting EHR meaningful use measures." ${ }^{\prime 9}$ Regarding a different provision allowing beneficiaries who see an ACO PCP to opt-out of having their claims data shared, ${ }^{20}$ the College of Healthcare Information Management Executives ("CHIME") retorted, "If beneficiary claims data are withheld, the ACO's ability to improve individual beneficiary health, as well as achieve the desired shared savings, could be compromised." 21

In the final regulations announced by CMS in late $2011^{22}$ the linkages between ACOs and MU were noticeably reduced. In particular the 50 percent meaningful user requirement was dropped. The final rule also dramatically reduced the number of quality measures that have to be reported. $^{23}$

Parallels between ACOs and MU are readily identified. For example, the core regulatory structures are built around similar matrices. Less positively, as one commentator observed, both fall on the government sword of "underestimat[ing] the costs associated with projects it champions, while at the same time overestimating savings. ${ }^{24}$ And, in both cases the industry is looking for the pot to be sweetened. If the ACO proposal fails or becomes sweetened to the extent industry desires, then the linkage drawn between HITECH and ACA may be regretted.

18. See, e.g., Ron Klar, Saving the Shared Savings Program (ACOs) Part Three: Quality, Payment, and Data Issues, Health Aff. Blog (June 6, 2011, 11:03 AM), $\mathrm{http}$ //healthaffairs.org/blog/2011/06/06/saving-the-shared-savings-program-acos-part-threequality-payment-and-data-issues/.

19. Memorandum from Michael Maves, Exec. Vice President, Am. Med. Ass'n, to Donald Berwick, Adm'r, Ctrs. for Medicare \& Medicaid Servs. 25 (June 3, 2011), available at http://www.ama-assn.org/esources/doc/washington/aco-shared-savings-comment-letter3june2011.pdf.

20. Medicare Shared Savings Program, supra note 13, at 19652.

21. Memorandum from Richard Correll, President \& CEO, CHIME \& Lynn Vogel, Chair, CHIME to Donald Berwick, Administrator, Ctrs. for Medicare \& Medicaid Servs. (May 10, 2011), http://www.cio-chime.org/advocacy/CHIME_comments_on_CMS_ NPRM_for_ACOs.pdf.

22. Ctrs. for Medicare \& Medicaid Servs., Medicare Shared Savings Program: Accountable Care Organizations, Final Rule (Oct. 20, 2011), available at http://www.ofr.gov/OFRUpload/OFRData/2011-27461_PI.pdf

23. See generally Molly Merrill, Final Rule Eases ACO Regulations, Lifts EHR Requirements, HEALTHCARE IT NEwS (Oct. 20, 2011), http://www.healthcareitnews.com /news/hhs-final-rules-eases-aco-regulations-lifts-ehr-requirements.

24. Anthony Guerra, Guerra On Healthcare: Beware Cost Of MU, ACOs, INFO WEEK (May 23, 2011, 12:31 PM), http://performancecomputing.com/news/healthcare/ policy/229625348. 


\section{EMR Qualms, PCAST and Interconnectivity}

Historically, the contentious component of the history of EMRs has been funding, not their ability to dramatically improve health care. Accordingly, the primary research findings publication in early 2011 stated there was "no association between EHR use and care quality for nineteen indicators and a positive relationship for only one indicator." ${ }^{, 25}$ In response, ONC staff published a literature review in Health Affairs in March 2011 that suggested a far more positive correlation of HIT to improved patient safety. ${ }^{26}$

There was better news out of HIT's bellwether state. According to a 2011 report by the California HealthCare Foundation, physician practices with an EMR in place sharply increased to forty-eight percent. In addition, the gains and penetration in larger practices for EMRs and for most forms of HIT, such as CPOE, e-prescribing, and decision support were notable. ${ }^{27}$

However, a far more serious challenge to ONC's approach to HIT had surfaced in The White House. Its full title was the President's Council of Advisors on Science and Technology, Report To The President Realizing The Full Potential of Health Information Technology To Improve Healthcare For Americans: The Path Forward. ${ }^{28}$ PCAST principally was concerned about the low level of transformation that IT had had on healthcare. Thus, the committee noted, "[i]n other sectors ... rapid progress has been catalyzed by wise technology choices that open up markets to competition and innovation." The barriers to HIT adoption identified by PCAST are generally known and include market failures (both network effects and misaligned incentives), privacy and security concerns, proprietary platforms, and the healthcare industry's somewhat parochial approach to health data.

Where PCAST was insightful (and clearly differed from the CMS/ONC approach) was in viewing data exchange as a major priority (for patient care, health research, and to create network value and so stimulate adoption) and in its skepticism for useful data exchange emerging from the current generation of EMRs, even when supported by Health Information Exchanges ("HIE").

25. Max J. Romano \& Randall S. Stafford, Electronic Health Records and Clinical Decision Support Systems: Impact on National Ambulatory Care Quality, 171 ARCHIVES OF INTERNAL MED. 897, 901 (2011).

26. Buntin et al., supra note 12 .

27. California HealthCare Found., The State of Health information TECHNOLOGY IN CALIFORNIA (2011), available at http://www.chcf.org/resources /download.aspx?id=\%7b31EF7F0D-D65D-4E6C-9B76-F0A8DA554B2C\%7d.

28. President's COUNCIL OF AdVISORS ON SCI. \& TECH., RePORT TO the PREsident REALIZING the Full Potential of Health Information TeChNOLOgy to IMPROVE HEALTHCARE FOR AMERICANS: THE PATH FORWARD (2010), available at http://www.whitehouse.gov/sites/default/files/microsites/ostp/pcast-health-it-report.pdf. 
While the CMS/ONC approach has been to concentrate on EMRs (requiring certification) and users (requiring MU), PCAST concentrated on less aggregated data. Specifically, its focus is less on a patient's medical record (containing all the data elements from a single provider) and more on the discrete data elements surrounding a patient from all providers. To be useful PCAST believes those data elements must be in a universal exchange language (likely an XML variant). This markup language would provide the metadata that provides patient identifying information, privacy protocols, and provenance relating to that data element. The other piece of the puzzle for PCAST was how to search for and collate these data elements. For PCAST the answer is data-element access services ("DEAS") - specialized and secured search engines that would crawl the meta-data and be able to respond to searches by patients or providers.

The critical regulatory pieces for PCAST therefore were that CMS/ONC should define a mark up language and require its use as part of the future MU stages, "define standards for the surfacing of metadata for use by the data element access services," and support the growth of DEAS. Although PCAST did not use this language, there was a distinct impression that the authors of PCAST believed that the stimulus money was being used to replace paper records silos with electronic ones. ${ }^{29}$

PCAST was fundamentally flawed, particularly in the way it approached privacy and security. ${ }^{30}$ It was quickly rejected by the EMR industry that preferred a document-centric approach and described the PCAST proposal "to manage clinical data and security at the individual data element level" as "unworkable." "31 By March 2011, the HIT Committee's PCAST workgroup and then the HIT Committee itself had rejected the PCAST proposals as based on untested theoretical models with enormous and unsolved privacy and operational issues. ${ }^{32}$ Notwithstanding, ONC must have seen some validity in the PCAST proposals, or at least appreciated the political power of its source. In August 2011 the agency published an

29. Id. at 70 .

30. Mark A. Rothstein, Debate Over Patient Privacy Controls in Electronic Health Records, HASTINGS CTR. BIOETHICS FORUM (Feb. 17, 2011, 10:09 AM), http://www.thehastingscenter.org/Bioethicsforum/Post.aspx?id=5139\&blogid=140\#ixzzlEY 7393PO.

31. Memorandum from the Electronic Health Record Ass'n to David Blumenthal, Nat'1 Coordinator, Office of the Nat'l Coordinator for Health Info. Tech. (Mar. 18, 2011), http://www.himssehra.org/docs/201104_BlumenthalLetterPCAST,pdf.

32. See Health Info. TeCh. Pol'y Comm., Summary of the March 2, 2011 Meeting (Mar. 3, 2011), http://healthit.hhs.gov/portal/server.pt/gateway/PTARGS_0_12811 95448 0_0_18/2011-03-02_policy_summary_final.pdf. See generally Anthony Guerra, Health IT Advisers Blast Data Exchange Policies, INFORMATIONWeEk (April 01, 2011, 11:14 AM), http://www.informationweek.com/news/healthcare/leadership/229400737. 
advanced NPRM for metadata standards albeit for summary care records. ${ }^{33}$

In early 2011, a report from PricewaterhouseCoopers ("PwC") complemented the PCAST critique. A key finding of "Putting patients into "Meaningful Use" ${ }^{34}$ was that "[t]o achieve the ultimate goal of patientcentered care" providers "need patients to buy into the concept and utilize the health IT tools supporting it. The implication of not involving patients early in the process might be lower and slower adoption and utilization of these tools. ${ }^{, 35}$ The report speculated that health systems had delayed work on their patient portals to deal with other MU requirements and noted that the MU criteria fail to measure patient engagement. To an extent, the PwC report looks at the PCAST lack of market innovation from the patient demand side. There are many reasons to be skeptical about personal health records. ${ }^{36}$ However, it does seem to be a reasonable argument that innovation and competition in the EMR space will happen only with a major increase in patient involvement and demand.

The disruption served by the developments outlined above was not fatal to the HITECH-mandated process. Yet, together the developments suggested that the CMS/ONC model had flaws and invited provider skepticism about the agencies' vision of stages 2 and 3 .

\section{PREVIEWING STAGES 2 AND 3}

As a result, rather than tamping down the anxiety (and lack of preparation) of potential recipients of HITECH largesse by providing a gentle ramp up in stage 1, the debate over the level of MU merely started all over again.

\section{A. The Escalator Problem}

Dr. Blumenthal liked to refer to what he called the "escalator problem": "[w]e have to get providers on the escalator, get them moving up the escalator, keep them on the escalator toward more and more sophisticated and demanding uses of electronic technologies. ${ }^{, 37}$ With the providers (or many of them) now on the escalator because of stage 1, the challenge in the next two stages is not to have "them running back down in terror at what

33. Metadata Standards To Support Nationwide Electronic Health Information Exchange, 42 C.F.R. $\$ 170$ (2011).

34. PwC Health Research Inst., Putting Patients Into "Meaningful Use" (2011), available at $\mathrm{http}: / / \mathrm{www}$.pwc.com/us/en/health-industries/publications/putting-patients-intomeaningful-use.jhtml.

35. Id. at 6 .

36. See generally Nicolas P. Terry, Personal Health Records: Directing More Costs and Risks to Consumers?, 1 DREXEL L. REV. 216 (2009).

37. David J. Brailer, Guiding the Health Information Technology Agenda, 29 HEALTH AFF. 586, 588 (2010). 
we've asked of them," yet at the same time not to allow the escalator "to turn into one of those airport moving walkways where you end up after a long trip at precisely the same altitude as where you started. ${ }^{, 38}$

By March 2011, CMS had moved many providers to the escalator having registered 25,217 eligible healthcare physicians and hospitals for the MUbased incentive programs. ${ }^{39}$ Initial payments were started shortly thereafter, with CMS paying out $\$ 75$ million by the end of May $2011 .^{40}$ The first certified meaningful user was a family practice physician in Plainville, Kansas. The first stimulus checks (for $\$ 18,000$ ) went to three Massachusetts physicians and to Beth Israel Deaconess Medical Center ( $\$ 2.57$ million). ${ }^{41}$ In August 2011, ${ }^{42} \mathrm{CMS}$ announced that 77,000 providers had registered for incentive payments and the Medicare and Medicaid programs had paid out $\$ 400$ million.

According to a 2011 Fitch Ratings report, not-for-profit hospitals that have implemented advanced HIT enjoyed higher profits and profit growth rates. ${ }^{43}$ Further, a 2010 McKinsey report estimated that, at least for hospitals, HIT investment could return its investment. ${ }^{44}$ Notwithstanding, the PwC survey discussed above ${ }^{45}$ suggested that fewer HITECH subsidy participants would achieve MU (down to 82 percent compared to 90 percent this time last year). In part, this scenario may have been exacerbated by the transition from ICD-9 to ICD-10 $0^{46}$ and changes to diagnosis and procedure

38. Id. at 588-89.

39. Mary Mosquera, CMS Has Paid Out $\$ 37.6 M$ in EMR Incentives So Far, Gov'T HEALTH IT (Mar. 25, 2011), http://govhealthit.com/news/cms-has-paid-out-376m-ehrincentives-so-far.

40. Press Release, CMS Office of Pub. Affairs, CMS Announces Financial Resources, Flexibility to Help Providers Use Health IT Systems (May 26, 2011), $\mathrm{http} / / / \mathrm{www} . \mathrm{cms}$.gov/apps $/ \mathrm{media} / \mathrm{press} /$ release.asp?Counter $=3968 \&$ intNumPerPage $=10 \& \mathrm{che}$ $\mathrm{ckDate}=\&$ checkKey $=\& \mathrm{srch}$ Type $=1$ \&numDays $=3500 \& \operatorname{srchOpt}=0 \& \mathrm{srchData}=\&$ keywordTyp e $=$ All \&chkNews Type $=1 \% 2 \mathrm{C}+2 \% 2 \mathrm{C}+3 \% 2 \mathrm{C}+4 \% 2 \mathrm{C}+5 \&$ intPage $=\&$ showAll $=\& \mathrm{p} Y$ ear $=\&$ yea $r=\&$ desc $=\&$ cboOrder $=$ date.

41. Chelsea Conaboy, BIDMC Receives Medicare Award for Electronic Health Records, BosTON GLOBE (May 26, 2011, 6:53 PM), available at $\mathrm{http}: / / \mathrm{www}$. boston.com/news/health/ blog/2011/05/beth_israel_dea_24.html. The first two Medicaid program payments were to the University of Kentucky Healthcare and two Oklahoma physicians. Mary Mosquera, $C M S$ Counts 4,000 Providers Initially Registering for EHR Incentives, GOV'T HEALTH IT (Jan. 07, 2011), http://www.govhealthit.com/news/cms-counts-4000-providers-initially-registeringehr-incentives.

42. Conn, supra note 7.

43. Melanie Evans, Advanced IT Linked with Hospital Profitability, Fitch Finds, MODERN HEALTHCARE (May 17, 2011, 11:00 AM), http://www.modernhealthcare.com /article/20110517/NEWS/305179953/.

44. Francois M. Laflamme et al., Reforming Hospitals with IT Investment, MCKINSEY QUARTERLY (Aug. 2010), http://www.mckinseyquarterly.com/Reforming_hospitals_with_IT investment_2653.

45. See PwC Health Research InST., supra note 34 , at 3.

46. Tom Sullivan, Would Meaningful Use Stage 2 Delay Ignite ICD-10?, Gov'T 
coding that CMS has mandated for all HIPAA transactions by October 1, $2013 .^{47}$ Further, the Fitch Ratings report estimated that the stimulus funds would offset approximately only 15 to 20 percent of the total expenditures necessary to meet $\mathrm{MU}$ requirements, straining HIT budgets during the HIPAA and ICD transitions. ${ }^{48}$

\section{B. Process and Pushback}

When the MU roadmap was published, three discrete stages were anticipated. Stage 2 criteria were to be published in late 2011 and stage 3 criteria to appear in late 2013. At the time that stage 1 was announced, it was thought that stages 2 and 3 would demand a more robust health information exchange (including orders and test results) and the ability of the data to better "follow" the patient. It was assumed that stage 2 would expand stage 1 criteria to encompass care delivery standards in the areas of disease management, clinical decision support, medication management, patient access to their own health information, transitions in care, quality measurement and research, and bi-directional communication with public health agencies. Subsequently, stage 3 would focus on decision support, self-management tools for patients, and improving population health outcomes.

A notice of proposed rulemaking ("NPRM") for stages 2 and 3 is expected in the first quarter of 2012 and as before is being spearheaded by the Meaningful Use Workgroup of the HIT Policy Committee ("HITPC"). ${ }^{49}$ The Workgroup included a spreadsheet of the proposed stage 2 and 3 Objectives and Measures in November 2010, ${ }^{50}$ and then presented its recommendations to the HITPC in December, ${ }^{51}$ after which HITPC opened up its recommendations for public comment in January $2011 .^{52}$

HEALTH IT (May 19, 2011), http://govhealthit.com/news/would-meaningful-use-stage-2delay-ignite-icd-10-efforts-or-not.

47. Ctrs. for Medicare \& Medicaid Servs., ICD-10 Overview (Sept. 8, 2011), http://www.cms.gov/ICD10/.

48. Laflamme et al., supra note 44.

49. Off. of Nat'l Coordinator for Health Info., Meaningful Use Workgroup (Sept. 19, 2011), http://healthit.hhs.gov/portal/server.pt?open $=512 \&$ objID $=1472 \&$ mode $=2$.

50. Off. Nat'l CoORdinator FOR Health INFo. TeCh. Improving Quality, Safety, Efficiency \& Reducing Health Disparities (2011), http://healthit.hhs.gov/portal/server.pt /gateway/PTARGS_0_0_5383_1472_17094_43/http\%3B/wcipubcontent/publish/onc/public _communities/u_z/wg_month_pages/mu_jan_portlet/files/overviewmuobjectives_muwg_11 $\overline{2} 310 . x 1 s$.

51. Paul Tang \& George Hripcsak, HIT Policy Committee Meaningful Use Workgroup (Dec. 13, 2010), http://healthit.hhs.gov/portal/server.pt/gateway/PTARGS_0_0_6010_1814 17824 _43/http\%3B/wci-pubcontent/publish/onc/public_communities/content/files/mu_recs_ 121310.ppt.

52. Off. Nat'l Coordinator for Health Info. TeCh., hit Policy Committee: Request for COMment Regarding the Stage 2 Definition of Meaningful Use of 
Perhaps there was no surprise when the patterns of action and argument from stage 1 started to reappear. Healthcare and HIT industries, physicians, and Congress began to cast doubts on the adequacy of funding for the initiative and sought to pressure CMS/ONC to make only modest upward changes in $\mathrm{MU}$ and/or delay stage 2.

The basic arguments can be discerned from some of the more than 400 comments sent to the HITPC regarding stage 2. For example, the American Hospital Association noted "[c]learly, the Stage 1 requirements are challenging; raising the bar significantly in Stage 2 risks limiting the success of the EHR incentive programs," and recommended that stage 2 "should not start until at least 75 percent of all eligible hospitals and physicians/professionals have successfully reached Stage 1, and not before FY 2014. ${ }^{, 53}$ Concurring, the Federation of American Hospitals pushed back against any new objectives being added in stage $2 .{ }^{54}$ The American Medical Association and thirty-eight other medical societies jointly recommended that physicians should be permitted to opt out of a measure that has little relevance to the physician's routine practice and should not be subjected to objectives that involved dependencies out of their control (such as patients accessing a portal or laboratories delivering test results).$^{55}$

The HIT industry was in broad agreement. In February 2011, the Healthcare Information and Management Systems ("HIMS") EMR Association urged a more conservative timeline for stage 2, ostensibly because of the inadequate schedule between publication (presumably in Q4 2011) of stage $2 \mathrm{MU}$ and certification criteria, software development, and implementation. ${ }^{56}$ Finite suggestions included, for example, limiting stage 2 to increased adoption of stage 1 measures and delaying stage 2 until 2014

ELECTRONIC HEALTH RECORDS (EHRS) (2011), http://healthit.hhs.gov/portal/server.pt/ gateway/PTARGS_0_0_5383_1472_17094_43/http;/wcipubcontent/publish/onc/public_com munities/u_z/wg_month_pages/mu_jan_portlet/files/nr_mu_rfc_v_4_2011_01_05.pdf.

53. Letter from American Hospital Ass'n to Joshua Seidman, U.S. Dept. of Health \& Human Servs. (Feb. 25, 2011), http://www.haponline.org/downloads/AHA_Comment Letter_on_Stage_2_Meaningful_Use_02252011.pdf.

54. Letter from Charles N. Kahn III, President \& CEO, Fed'n of American Hospitals, to David Blumenthal, Chair, Nat'l Coordinator for Health Info. Tech. (Feb. 25, 2011), http://www.fah.org/fahCMS/Documents/On\%20The\%20Record/Public\%20Comments/2011/ ONC_Itr_re_Stage_2_Meaningful_Use.pdf. See also Letter from College of Healthcare Info. Mgmt. Executives to Joshua Seidman, Dept. of Health \& Human Serv. (Feb. 18, 2011), http://www.cio-chime.org/advocacy/CHIME_Stage_2_MU_CommentsLetter_to_Seidman February_2011.pdf.

55. Letter from American Academy of Dermatology Assoication et al. to Joshua Seidman, Off. Of the Nat'1 Coordinator for Health Info. Tech. (Feb. 25, 2011), http://www.ama-assn.org/ama1/pub/upload/mm/399/comments-hitpc-proposed-measures25 feb2011.pdf.

56. Letter from HIMSS Electronic Health Record Ass'n to Paul C. Tang, Meaningful Use Workgroup Chairperson, Health Info. Tech. Policy Comm., http://www.himssehra.org/docs/20110223\%29EHRA_Stage2MU.pdf. 
(i.e., retrospectively changing stage 1 to 2011-13).

In contrast, 25 consumer advocacy organizations, led by National Partnership for Women \& Families and including AARP, the AFL-CIO, and Consumers Union, filed a very positive comment approving of the movement of menu objectives to core, the use of evidence as key to decision support, the incorporation of advance directive information, and of general patient interaction. ${ }^{57}$

At Congressional hearings held in June 2011 some in industry took the position that $\mathrm{MU}$ is dominated by compliance and so industry energies are aimed at compliance rather than innovation. ${ }^{58}$ Testifying, the CEO of a well-known HIT company stated:

Whether Meaningful Use standards are right or wrong is not the real issue. What is important is that today, the end-users, doctors and patients, are further away than ever from system design, because new product development is focused on satisfying those regulatory hurdles, rather than on simple innovations that improve productivity. As a result, program requirements are disruptive to the processes in place in increasingly busy offices. $^{59}$

A dermatologist testifying before the same panel argued that "there are significant barriers to full-scale adoption and implementation of HIT specifically, cost, regulatory barriers, financial penalties, an unpredictable marketplace and system integration" and, specifically, doctors "investing in EHRs are struggling with the structure of the CMS Meaningful Use timeline. 60

By May 2011, HITPC was discussing some more conservative options and at its June 8 , meeting accepted the recommendations of the $\mathrm{MU}$ Workgroup that stage 2 be delayed by one year. ${ }^{61}$ The Workgroup accepted

57. Letter from Consumer Partnership for eHealth to Joshua Seidman, Off. Of the Nat'l Coordinator for Health Info. Tech. (Feb. 25, 2011), http://www.nationalpartnership.org

/MU2. See also Consumer Partnership for eHealth, 10 Arguments You May Have Heard About the Meaningful Use Proposed Rule... And the Consumer Response, http://www.nationalpartnership.org/site/DocServer/10_Arguments_FINAL.pdf?.

58. House Comm. on Small Bus., Subcomm. on Health Care \& Tech., Not What the Doctor Ordered: Health IT Barriers for Small Medical Practices (June 2, 2011), http://smbiz.house.gov/Calendar/EventSingle.aspx?EventID=243286.

59. Statement of Andy Slavitt, Chief Executive Officer, OptumInsight to the Subcommittee on Healthcare \& Tech. Subcomm. on Small Bus. (June 2, 2011), http://smbiz.house.gov/UploadedFiles/Slavitt_Testimony.pdf.

60. Statement of Sasha Kramer, FAAD to U.S. House of Rep. Small Business Committee Health \& Technology Subcommittee (June 2, 2011), http://smbiz.house.gov/ UploadedFiles/Kramer_Testimony.pdf.

61. Letter from Paul Tang, Vice Chair, Health IT Policy Committee to Farzad Mostashari, Nat'l Coordinator for Health Info. Tech. (June 8, 2011), http://healthit.hhs.gov /portal/server.pt/document/954839/muwg-recommendations-06-08- 
that "compliance with stage 2 MU objectives in 2013 poses a nearly insurmountable timing challenge for those who attest to meaningful use in 2011 " because of the time crunch associated with the anticipated publication of the stage 2 final rule in June 2012, but the expectation that newly certified software would be in use by eligible hospitals in October of that same year. This delay would apply only to the early entrant group, i.e., those who attest in 2011. Stage 1 attesters beginning in 2012 would face the same 2014 MU deadline.

Generally CMS/ONC has stayed the course on its basic approach to stage 2. Measures have been ramped up for about half the objectives, menu objectives have been moved to core, and several new objectives have been added, particularly with regard to engaging patients. For example, there are new objectives relating to patient access to EHRs, electronic discharge instructions, clinical summaries, and secure online messaging between patients and providers. The stage 1 requirement of recording the existence of an advance directive has now been supplemented with the requirement to record the directive itself.

If the HITPC draft is accepted by CMS/ONC, a notice of proposed rulemaking should be published in late 2011. The areas of criticism have already been flagged by industry players and no doubt will be vociferously re-argued during the NPRM process. The question will be whether CMS/ONC, having conceded the timing issue for 2011 attesters, holds firm on the rest of stage 2. Looking forward, 2015's Stage 3 is likely to include provisions relating to telehealth (particularly for in-home monitoring), ethnographic research, and additional patient-generated data such as survey and self-monitoring data. ${ }^{62}$

\section{ASSESSING PROGRESS}

It is important to recall the immensity of the task that HITECH assigned to these three sets of players (regulators, HIT vendors, and healthcare providers). To merely distribute such a large amount of government funding in the MU timeframe would be a considerable undertaking. To do so following the statutory criteria and on a timeline designed to have rapid economic impact while simultaneously educating two major industries on the future of HIT is a monumental task. Steve Lohr has described it as a "grand experiment" and a "huge challenge in innovation design." ${ }^{, 63}$ This experiment does not operate in a vacuum. Existing programs such as e-

11 pdfhttp://healthit.hhs.gov/portal/server.pt/gateway/PTARGS_0_12811_954836_0_0_18/ muwg-recommendations-06-08-11.pdf.

62. Genevieve Douglas, Mobile Health Technology, Telemedicine Will Be Included in MU Stage 3, ONC Says, BNA Health IT LAW \& INDUSTRY REP., Aug. 1, 2011.

63. Lohr, supra note 10. 
prescribing $^{64}$ or new ones such as ACOs need to be integrated. Finally, ONC is working with nothing resembling a clean sheet of paper: it does not control records technologies, such as their disparate interfaces, ${ }^{65}$ merely some of their expected functions.

Excuses and obstacles aside, the core question remains: whether HITECH and its MU touchstone will transcend stimulus fund status as a public works project and transform US healthcare? In a blog post as he was departing ONC, Dr. Blumenthal lauded the adoption numbers the stimulus program had achieved:

In the last two years, however, there has been a significant upward inflection in the adoption rate. For primary care providers, adoption of a basic EHR increased by half from 19.8 percent in 2008 to 29.6 percent in 2010. And with HITECH Act programs now in full swing, it looks clear that adoption and use of health information technology will go into high gear. Already, 81 percent of hospitals and 41 percent of office physicians are saying they intend to achieve meaningful use of EHRs and qualify for Medicare and Medicaid incentive payments. ${ }^{66}$

Those and other ${ }^{67}$ figures supply an excellent answer but not necessarily to the correct question. Spending $\$ 27$ billion to buy EMR systems is always going to increase EMR adoption. Indeed, a 2011 survey found that the strongest driver for EMR implementation continued to be the MU incentives rather than any endogenous features. ${ }^{68}$ The far more difficult questions are whether that adoption of EMRs will be transformational; whether providers will continue to use, update, and replace EMR systems when the stimulus money is gone; and whether investment and innovation will continue? Will the less visible state-based HIE proposals find traction?

It is highly unlikely that there will be a single answer to any of these questions because the MU-regulated expenditures likely will have disparate impacts on different groups of providers. The trend of extracting high value

64. U.S. Gov't Accountability Office, GAO-11-159, Electronic Prescribing: CMS Should Address Inconsistencies in Its Two Incentive Programs That Encourage the Use of Health Information Technology (2011).

65. See, e.g., Am. Med. Ass'n, AMA Adopts New Policies at Annual Meeting (June 21, 2011), http://www.ama-assn.org/ama/pub/news/news/al l-new-policies.page.

66. David Blumental, HITECH in High Gear, HealTHIT Buzz (Feb. 15, 2011, 10:09 AM), http://healthit.hhs.gov/blog/onc/index.php/2011/02/15/hitech-in-high-gear/.

67. Joseph Goedert, Report Suggests a Surge in EHR Purchases, Health Data MGMT. (June 21, 2011), http://www.healthdatamanagement.com/news/survey-capsite-ehr-electronic -health-records-physicians-ambulatory-42670-1.html (reporting survey results suggesting that EMR purchases would double in 2011).

68. Molly Merrill, Survey Reveals Docs' Perceptions of EHRs as Potential Buyers, Users, HEALTHCARE IT NEws, Aug. 08, 2011, http://www.healthcareitnews.com/news /survey-reveals-docs-perceptions-ehrs-potential-buyers-users. 
from HIT will continue among major vertically integrated providers (such as the VA, Kaiser Permanente, and Intermountain Healthcare). Equally, the penetration of EMRs in larger institutions likely will have "bought" the latest generation of residents who will never want to practice without the technology ${ }^{69}$ However, the jury remains out with regard to most providers (particularly the smaller ones). They are on the escalator, but likely will have their hands out for another round of subsidies beginning in 2015 or be a large enough group that will render the scheduled imposition of Medicare penalties politically unacceptable.

Although seriously flawed, the PCAST report did identify a root problem with the CMS/ONC strategy: without insisting on interoperability through MU there is the danger of replacing paper silos with electronic ones. Without innovation fueled by technology (PCAST) and consumer demand fueled by engagement (PwC), it is hard to see improving the ROI in most HIT deployments or the end of the market failure problems.

\section{CONCLUSION}

All along there was an apparently sensible consensus that a "Son of HIPAA" ${ }^{\text {"70 }}$ was not the solution to the under-utilization of HIT. But in retrospect, given a conservative regulatory (MU) approach and the continued chronic failure of the healthcare industry to willingly engage in bending its own cost curve, it is tempting to ask whether we would have done better by mandating the industry to internalize the costs. Maybe, like so much of the healthcare "reform" we endure, the MU-regulated process is just another symptom of a broken healthcare system that will not be remedied until a single provider model becomes politically acceptable.

69. Compare the cohort that is closer to retirement. See Lena H. Sun, Despite Incentives, Doctors Are Wary About Switching to Electronic Health Records, WASH. POST, Mar. 14, 2011, available at http://www.washingtonpost.com/national/despite-incentives-doctors-arewary-about-switching-to-electronic-health-records-/2011/02/24/ABvRCuV_story.html ("The costs 'are the biggest holdback nationwide,' said Sussman, 64. 'Doctors who are my age, in their early 60 s, maybe will retire out. They may think, 'I don't need this bother; it's going to cost more money and cost more time."').

70. See generally Nicolas P. Terry, To HIPAA, A Son: Assessing the Technical, Conceptual, and Legal Frameworks for Patient Safety Information, 12 WIDENER L. REV. 133 (2005) 
